\title{
Searching for perfection: further progress in management of chemotherapy-induced nausea and vomiting-introduction
}

\author{
Matti Aapro ${ }^{1}$ \\ Received: 11 December 2017 / Accepted: 12 January 2018 / Published online: 19 March 2018 \\ (C) The Author(s) 2018
}

Emesis is an evolutionary reflex designed to protect the body from ingested toxins. Many treatments, including chemotherapeutic agents, to varying degrees, are also felt to be toxins by the body and can elicit an immediate or delayed reaction involving nausea and vomiting. Chemotherapy-induced nausea and vomiting (CINV) is a common side effect of many anticancer therapies and significantly reduces patient quality of life [1]. CINV can also lead to treatment interruption, dose reduction, and early discontinuation, which compromise the effectiveness of these therapies and negatively impacts longterm patient outcomes. Significant gains in the prevention and management of CINV have emerged over the last two decades. Without antiemetic prophylaxis, more than $90 \%$ of patients receiving highly emetogenic chemotherapy (HEC) are at risk for emesis $[2,3]$. In contrast, a recent metaanalysis of clinical trials investigating modern-day antiemetic therapy in patients receiving HEC showed rates of vomiting and significant nausea ranging from approximately 10 to $40 \%$ [4]. The achievements in CINV prophylaxis are reflected in a worldwide online survey conducted by the American Society of Clinical Oncology (ASCO) in 2014, in which antiemetic therapy was voted one of the "Top 5 Advances in Modern Oncology" [5].

From a patient's perspective, even a short duration of nausea or a few vomiting events can be very troublesome and represent an unacceptable outcome. Thus, the goal for CINV management should be complete control of both nausea and vomiting, an achievement that remains elusive for many patients. CINV is classified into five main types: acute, delayed, breakthrough, anticipatory, and refractory [1]. Events occur-

Matti Aapro

maapro@genolier.net

1 Cancer Centre, Clinique de Genolier, Case Postale, Route du Muids 3, (PO Box) 100, 1272 Genolier, Switzerland ring within $24 \mathrm{~h}$ following chemotherapy administration are considered acute and often peak at 5 to $6 \mathrm{~h}$ post-chemotherapy. Delayed CINV occurs on days 2 to 5 , and sometimes beyond due to disruption of normal small bowel peristalsis, and has historically been more difficult to prevent. Despite appropriate prophylactic treatment, some patients experience breakthrough CINV during chemotherapy or refractory CINV in subsequent cycles of therapy and require more aggressive antiemetic therapy. Anticipatory CINV is perhaps the most challenging class to address and occurs as a conditioned response resulting from a negative experience with CINV in previous cycles of chemotherapy. Environmental cues, such as the sights and smells of the clinic, and patient anxiety can also contribute to anticipatory CINV.

Important advances in the last 25 years have revolutionized the prevention and management of CINV, allowing patients to complete their chemotherapy course and continue their daily activities. However, CINV remains a substantial clinical challenge and unmet needs persist, as discussed by Dr. Matti Aapro in the first article of this supplement. Current prevention and management of CINV is informed by a number of consensus guidelines, which are continuously updated to reflect the evolution in this area of supportive care [2, 6, 7]. In the second article, Dr. Mark Clemons will highlight important updates to current CINV guidelines and discuss emerging risk prediction models seeking to improve the individualization of antiemetic therapy. Dr. Lee Schwartzberg will then provide an overview of recent clinical trial data focused on the different classes of antiemetic therapy and how these agents impact the CINV landscape. Lastly, Dr. David Warr will provide expert insights into two challenging clinical scenarios in CINV to emphasize the important factors to consider when selecting optimal antiemetic prophylaxis and managing breakthrough CINV.

Acknowledgements The author would like to thank Tristin Abair, $\mathrm{PhD}$, for her assistance in drafting the manuscript and Trudy Grenon Stoddert, ELS, for her editorial assistance and assistance with preparing the manuscript for submission. 
Financial support This educational activity is supported by grants from Merck and Co, Inc. and TESARO, Inc.

\section{Compliance with ethical standards}

Conflict of interest Dr. Aapro has disclosed that he has received consulting fees or honoraria from Amgen. He has also received payment for lectures and/or support for travel from Amgen, Helsinn, Hospira, Johnson \& Johnson, Novartis, Pierre Fabre Medicament, Roche, Sandoz, TESARO, Teva, and Vifor Pharma. Dr. Aapro has received research funding from Helsinn, Hospira, Novartis, Pierre Fabre Medicament, and Sandoz. He has also disclosed receiving fees for participation in advisory or review activities from Helsinn Healthcare, Hospira, Merck, Merck KGaA, Pierre Fabre Medicament, Sandoz, TESARO, Teva, and Vifor Pharma.

Open Access This article is distributed under the terms of the Creative Commons Attribution-NonCommercial 4.0 International License (http:// creativecommons.org/licenses/by-nc/4.0/), which permits any noncommercial use, distribution, and reproduction in any medium, provided you give appropriate credit to the original author(s) and the source, provide a link to the Creative Commons license, and indicate if changes were made.

\section{References}

1. Navari RM, Aapro M (2016) Antiemetic prophylaxis for chemotherapy-induced nausea and vomiting. N Engl J Med 374: 1356-1367. https://doi.org/10.1056/NEJMra1515442
2. Roila F, Molassiotis A, Herrstedt J, participants of the MASCC/ ESMO Consensus Conference Copenhagen 2015 et al (2016) 2016 MASCC and ESMO guideline update for the prevention of chemotherapy- and radiotherapy-induced nausea and vomiting and of nausea and vomiting in advanced cancer patients. Ann Oncol 27(suppl 5):v119-v133. https://doi.org/10.1093/annonc/mdw270

3. Grunberg SM, Osoba D, Hesketh PJ et al (2005) Evaluation of new antiemetic agents and definition of antineoplastic agent emetogenicity - an update. Support Care Cancer 13:80-94. https:// doi.org/10.1007/s00520-004-0718-y

4. Abdel-Rahman O (2016) Neurokinin-1 inhibitors in the prevention of nausea and vomiting from highly emetogenic chemotherapy: a network meta-analysis. Ther Adv Med Oncol 8:396-406. https:// doi.org/10.1177/1758834016654902

5. American Society of Clinical Oncology. Top 5 Advances in Modern Oncology. Available at: https://www.asco.org/research-progress/ cancer-progress/top-5-advances-modern-oncology. Accessed 27 June 2017

6. National Comprehensive Cancer Network (NCCN). Clinical Practice Guidelines in Oncology (NCCN Guidelines $\left.{ }^{\circledR}\right)$ : Antiemesis. Version 2.2017. Available at: https://www.nccn.org/professionals/physician_ gls/pdf/antiemesis.pdf. Accessed 27 June 2017

7. Hesketh PJ, Kris MG, Basch E, et al (2017) Antiemetics: American Society of Clinical Oncology Clinical Practice Guideline Update. J Clin Oncol 35:3240-3261 